\title{
Análise preliminar de riscos (APR) de uma obra residencial unifamiliar na cidade de Candeias/MG
}

A construção civil apresenta dados alarmantes no que diz respeito à exposição dos trabalhadores aos riscos ocupacionais os quais existem nas mais diversas atividades que o setor oferece, colocando em risco a saúde e integridade física desses colaboradores. Nesse sentido, o presente trabalho teve por objetivo aplicar a técnica de análise preliminar de riscos nas atividades executadas pelos trabalhadores e no processo construtivo de uma obra residencial unifamiliar no município de Candeias, Minas Gerais. Para isso, foram verificadas as condições dos equipamentos utilizados, análise do ambiente laboral, verificação dos dispositivos de proteção individual e coletivos, bem como as instalações das máquinas e equipamentos. A partir dos dados obtidos foram realizadas a análise dos riscos existentes e estudo da severidade e probabilidade dos mesmos. A análise foi feita observando os métodos de trabalho realizados rotineiramente na obra. Após o reconhecimento dos riscos, estes foram apresentados e discutidos com os colaboradores para que fosse possível propor medidas de controle afim de reduzir ou eliminar tais riscos, bem como, proporcionar treinamentos e uma maior conscientização nesse ambiente laboral.

Palavras-chave: Segurança no trabalho; Matriz de risco; Normas Regulamentadoras; Gestão de riscos; Construção civil.

\section{Preliminary risk analysis (APR) of a unifamiliar residential work in Candeias/MG}

Civil construction presents alarming data regarding the exposure of workers to occupational risks, which exist in the most diverse activities that the sector offers, putting at risk the health and physical integrity of these employees. In this sense, the objective of this study was to apply the preliminary risk analysis technique in the activities carried out by the workers and in the construction process of a single-family residential project in the municipality of Candeias, Minas Gerais. For this, the conditions of the equipment used, analysis of the work environment, verification of the individual and collective protection devices, as well as the installations of the machines and equipment were verified. From the obtained data, the analysis of the existing risks and their severity and probability were analyzed. The analysis was made observing the work methods routinely performed in the work. After risk recognition, these were presented and discussed with employees so that control measures could be proposed in order to reduce or eliminate such risks, as well as provide training and awareness in this work environment.

Keywords: Safety at work; Risk matrix; Regulatory standards; Risk management; Civil construction.

Douglas Lamounier Faria (iD

Universidade Federal de Lavras, Brasil http://lattes.cnpq.br/2575514568061593 http://orcid.org/0000-0002-5405-8430 douglas.lamounier@yahoo.com

Daiane Erika Lopes

Universidade Federal de Lavras, Brasil http://lattes.cnpq.br/5390075896006370

http://orcid.org/0000-0003-4243-3130 daianelopes899@gmail.com

Tony Matheus Carvalho Eugênio (iD Universidade Federal de Lavras, Brasil http://lattes.cnpq.br/0823437440133853 http://orcid.org/0000-0001-7049-2862 tony.matheus@hotmail.com

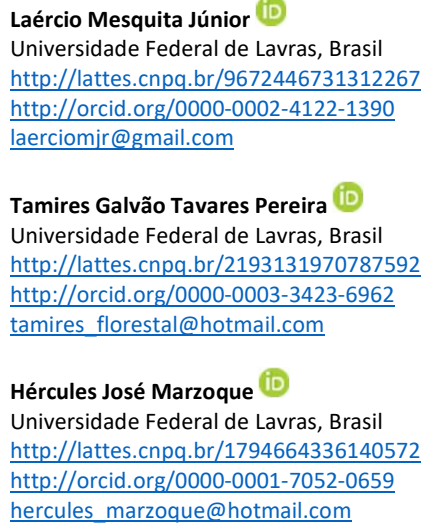

Tamires Galvão Tavares Pereira (iD Universidade Federal de Lavras, Brasil http://lattes.cnpq.br/2193131970787592

http://orcid.org/0000-0003-3423-6962 tamires florestal@hotmail.com

Hércules José Marzoque

Universidade Federal de Lavras, Brasil http://lattes.cnpq.br/1794664336140572

http://orcid.org/0000-0001-7052-0659

hercules marzoque@hotmail.com

\begin{abstract}
Thiago Moreira Cruz
Universidade Federal de Lavras, Brasil http://lattes.cnpq.br/7811942414257946 http://orcid.org/0000-0003-2808-1810 thiago.moreira.cruz@gmail.com

Marcelo Linon Batista

Centro Universitário de Lavras, Brasil http://lattes.cnpq.br/1905350618721525 http://orcid.org/0000-0002-7744-6049 marclinon@yahoo.com.br

Érica de Alvarenga Crespo Rodrigues (it) Centro Universitário de Lavras, Brasil http://lattes.cnpq.br/1688303514659757 http://orcid.org/0000-0002-4373-8254 eacrespo26.ea@gmail.com
\end{abstract}

Referencing this:

FARIA, D. L.; LOPES, D. E.; EUGÊNIO, T. M. C.; MESQUITA JÚNIOR, L.; PEREIRA, T. G. T.; MARZOQUE, H. J.; CRUZ, T. M.; BATISTA, M. L.; RODRIGES, É. A. C.. Análise preliminar de riscos (APR) de uma obra residencial unifamiliar na cidade de Candeias/MG. Scire Salutis, v.10, n.2, p.88-97, 2020. DOI: http://doi.org/10.6008/CBPC2236$\underline{9600.2020 .002 .0011}$ 


\section{INTRODUÇÃO}

A indústria da construção civil possui papel importante na economia brasileira e mundial, pois é um setor bastante heterogêneo que envolve diversos outros setores da economia, os quais servem de base para a execução das diversas obras e serviços. Mesmo sendo uma grande fonte geradora de emprego e renda, a construção civil é responsável por uma grande parcela dos acidentes de trabalho que ocorrem no Brasil, isso se deve à baixa qualificação dos profissionais, ausência de treinamentos, e baixos investimentos em saúde e segurança do trabalho.

Segundo Martinelli Filho et al. (2018), o setor da Construção Civil emprega 8,58\% da população ocupada do país e é responsável por uma parcela importante do Produto Interno Bruto - PIB nacional, participando com 6,1\% do PIB. Pela sua importância social e econômica é necessário analisar o comportamento dos acidentes de trabalho na construção civil.

Yi et al. (2012) afirmam que "a prevenção de acidentes na indústria da construção tem sido abordada a partir de múltiplas perspectivas, relacionadas a procedimentos de gestão de segurança para a adoção de tecnologias mais seguras de construção". Diversas são as técnicas que auxiliam a analisar e avaliar os riscos de um processo procurando identificar os fatores que possuem a maior probabilidade de causar os acidentes, para que se possam encontrar medidas que eliminem ou reduzam esses fatores. Entre essas técnicas estão a Análise Preliminar de Riscos (APR), Análise de Árvore de Falhas (FTA) e a Técnica de Incidentes Críticos (TIC).

A Análise Preliminar de Riscos (APR) permite que sejam levantados os principais riscos/perigos de forma qualitativa existentes num determinado processo, portanto sua aplicação em um setor que é marcado pela ocorrência numerosa de acidentes de trabalho, certamente contribuirá para a melhoria da saúde e da qualidade de vida de muitos trabalhadores no país. A partir da identificação dos riscos e dos agentes geradores desses riscos, é possível adotar medidas que tenham por objetivo a neutralização/eliminação dos mesmos ou minimização das consequências geradas por eles.

De acordo com França et al. (2008), o objetivo da APR é definir os riscos e as medidas preventivas antes da fase operacional. Utilizando como metodologia a revisão geral de aspectos de segurança, através de um formato padrão, levantando as causas e efeitos de cada risco, medidas e prevenção ou correção e categorização dos riscos. Ainda segundo Faria (2011), a APR também pode ser utilizada como ferramenta de revisão geral de segurança, avaliando de tempos em tempos os riscos do processo que possam não ter sido levantados anteriormente.

Nesse contexto, teve-se por objetivo fazer o levantamento e reconhecimento dos principais riscos ocupacionais que os trabalhadores de uma construção residencial unifamiliar estão expostos na etapa de execução de elementos estruturais de concreto armado (montagem de armaduras de aço, montagem de formas e concretagem de elementos estruturais), através da técnica de Análise Preliminar de Riscos (APR). Afim de se propor medidas protetivas, diminuindo assim, os acidentes e doenças ocupacionais que tanto acometem este ambiente laboral. 


\section{REVISÃO TEÓRICA}

\section{Acidentes na construção civil}

Em 2017 a indústria da construção civil no Brasil apresentou uma perspectiva diferente em relação à 2016. Após um período de instabilidade no setor a construção tem se mostrado cada vez mais produtiva. Em 2016 a retração foi de 5,2\%, já em 2017 houve retração de 5,0\%, segundo balanço divulgado pelo Instituto Brasileiro de Geografia e Estatística (IBGE, 2018). Com efeitos diversos no desenvolvimento do país, destacado os efeitos favoráveis sobre a produção, a renda, o emprego e os tributos, bem como seu forte encadeamento setorial. Ainda se ressalta que este é um setor com fortes impactos diretos, indiretos e induzidos na economia nacional, gerador de relevantes externalidades positivas sobre a base produtiva, sendo estratégico para o desenvolvimento econômico e social do país.

Porém existem fatores desfavoráveis no setor que é deficiente em muitos pontos como: no desperdício de material, mão de obra desqualificada, geração de grandes quantidades de resíduos sólidos e, sobretudo altos índices de acidente do trabalho. Segundo a Organização Internacional do Trabalho (OIT, 2017) a construção civil é o setor que apresenta os maiores números de acidentes de trabalho. Entre esses acidentes a maior causa identificada são as quedas em altura, soterramento e eletricidade (SILVA, 2008).

Muitas são as definições de acidente de trabalho e variam segundo o enfoque. O conceito legal para definir acidente pode ser encontrado na Lei no 8.213, de 24 de Julho de 1991 da Previdência Social. Art. 19. Acidente do trabalho é o que ocorre pelo exercício do trabalho a serviço da empresa ou pelo exercício do trabalho dos segurados referidos no inciso VII do art. 11 desta Lei, provocando lesão corporal ou perturbação funcional que cause a morte ou a perda ou redução, permanente ou temporária, da capacidade para o trabalho.

\section{Análise Preliminar de Riscos (APR)}

Análise Preliminar de Riscos - APR é um método de análise de perigos e riscos que incide em identificar acontecimentos inseguros, causas e resultados e determinar meios de controle. Preliminar, porque é empregada como primeira abordagem do objeto de estudo. Em um número relevante de acontecimentos é suficiente para determinar procedimentos de controle de riscos. De acordo com Tavares (2010) a "Análise Preliminar de Riscos (APR) é a análise, durante a fase de concepção ou desenvolvimento de um novo sistema, com o objetivo de se determinar os riscos que poderão estar presentes na sua fase operacional". Contudo, segundo Faria (2011), a APR também pode ser utilizada como ferramenta de revisão geral de segurança, avaliando de tempos em tempos os riscos do processo que possam não ter sido levantados anteriormente.

Segundo Sherique (2011), a elaboração de uma APR passa por algumas etapas básicas: a) Revisão de problemas conhecidos: a busca por analogias ou similaridades com outros sistemas; b) Revisão da missão a que se destina: atentar aos objetivos, exigências de desempenho, principais funções e procedimentos, estabelecer os limites de atuação e delimitar o sistema; c) Determinação dos riscos principais: apontar os 
riscos com potencialidade para causar lesões diretas imediatas, perda de função, danos a equipamentos e perda de materiais; d) Revisão dos meios de eliminação ou controle de riscos: investigar os meios possíveis de eliminação e controle de riscos, para estabelecer as melhores opções compatíveis com as exigências do sistema; e) Analisar os métodos de restrição de danos: encontrar métodos possíveis e eficientes para a limitação dos danos gerados pela perda de controle sobre os riscos; f) Indicação de quem levará a sério as ações corretivas e/ou preventivas: Indicar responsáveis pela execução de ações preventivas e/ou corretivas, designando também, para cada unidade, as atividades a desenvolver.

Segundo Catai (2012), para o desenvolvimento de uma APR, deve-se realizar o levantamento de todos os riscos existentes no local de trabalho e em seguida fazer a caracterização dos mesmos identificando suas principais causas e efeitos. Dessa forma será possível a elaboração de ações e medidas de prevenção ou correção das possíveis falhas detectadas. Como consequência, prioriza-se as ações que dependem da caracterização dos riscos, ou seja, quanto mais prejudicial ou maior for o risco, mais rapidamente deve ser solucionado.

\section{MATERIAIS E MÉTODOS}

\section{Área de estudo}

Este trabalho foi desenvolvido em uma obra de uma residência unifamiliar de área construída de 100 $\mathrm{m}^{2}$, situada na cidade de Candeias/MG. A obra era composta por sala, cozinha, banheiro, garagem, suíte, quarto, área de claridade e área de serviço; que se encontrava na fase de execução de estruturas de concreto armado.

\section{Levantamento de dados}

O presente estudo corresponde a uma pesquisa aplicada, pois utiliza conhecimentos de segurança e saúde no trabalho para aplicação em uma atividade do setor da construção civil e visa descrever o problema em discussão, caracterizando o objeto de estudo. Os riscos serão levantados nos serviços executados no Canteiro de Obras de uma residência unifamiliar, no qual consta de uma casa, com área de 100,00m², localizada em Candeias/MG. A pesquisa teve uma abordagem qualitativa que é a metodologia de pesquisa não estruturada, exploratória, pois considerou interpretações de gerenciamento de risco, considerando o entendimento dos processos como um dos objetivos, não havendo tratamento estatístico para os dados levantados.

Foi realizada uma avaliação dos riscos existentes na etapa de execução de elementos estruturais de uma obra de construção civil (residência unifamiliar) e após a análise desses riscos foram propostas medidas que visam neutralizá-los ou minimizar as consequências geradas por eles, objetivando contribuir com a adoção de medidas que proporcionem benefícios relacionados à saúde e segurança no trabalho. Esse trabalho se caracteriza ou como uma pesquisa bibliográfica associada a um estudo de caso, pois foram utilizados dados de trabalhos anteriormente publicados e também levantados em campo. 
A estrutura da pesquisa consistiu em: formulação do problema, englobando a justificativa do estudo; a determinação dos objetivos; a contextualização da problemática e definição da metodologia; realização do levantamento teórico, que orienta a caracterização do objeto de estudo; as definições e conceitos a serem utilizados em análise e correntes de pensamentos que norteiam a hipótese da pesquisa; levantamento de dados em campo e a discussão sobre as melhorias que possam acarretar. Os dados coletados em campo foram organizados e utilizados para elaboração da Planilha de Análise Preliminar de Riscos (APR).

\section{Criação da APR}

A escolha da aplicação da APR deve-se ao fato de ser uma análise preliminar, com uma análise inicial de partida e de origem qualitativa. Apesar de seu escopo básico de análise, é muito útil como revisão geral de segurança em sistemas operacionais. Para que as ações destinadas à prevenção sejam priorizadas, Catai (2012) criou a categorização dos riscos em sua avaliação de riscos, referente à severidade, em cinco categorias, apresentada de acordo com a Figura 1.

\begin{tabular}{|c|c|c|c|}
\hline \multicolumn{2}{|c|}{ DESCRIÇÃo } & AFASTAMENTO \\
\hline 01 & Leve & $\begin{array}{c}\text { Acidentes que não provocam lesōes (batidas leves, } \\
\text { arranhōes). }\end{array}$ & Sem afastamento. \\
\hline 02 & Moderado & $\begin{array}{c}\text { Acidentes com afastamento e lesōes não } \\
\text { incapacitantes (pequenos cortes, torçôes leves). }\end{array}$ & $\begin{array}{c}\text { Afasta mento de 01 a 30 } \\
\text { dias. }\end{array}$ \\
\hline 03 & Grande & $\begin{array}{c}\text { Acidentes com afastamentos e lesōes } \\
\text { incapacitantes, sem perdas de substâncias ou } \\
\text { membros (fraturas, cortes profundos) }\end{array}$ & $\begin{array}{c}\text { Afastamento de 31 a 60 } \\
\text { dias. }\end{array}$ \\
\hline 04 & Severo & $\begin{array}{c}\text { Acidentes com afastamentos e lesōes } \\
\text { incapacitantes, com perdas de substâncias ou } \\
\text { membros (perda de parte do dedo). }\end{array}$ & $\begin{array}{c}\text { Afastamento de 61 a 90 } \\
\text { dias. }\end{array}$ \\
\hline 05 & Catastrófico & Morte ou invalidez permanente. & $\begin{array}{c}\text { Não hà retorno à } \\
\text { atividade la boral. }\end{array}$ \\
\hline
\end{tabular}

Figura 1: Nível de severidade de acidentes que possam ocorrer. Fonte: Catai (2012).

Já em relação às categorias de risco referentes à de frequência, Catai (2012) apresenta os cinco níveis da categoria, descritos na Figura 2.

\begin{tabular}{|c|c|c|c|}
\hline GRAU & OCORRÊNCLA & DESCRIÇÃo & FREQUÊNCIA \\
\hline 01 & Improvável & $\begin{array}{c}\text { Baixissima probabilidade de ocorrer o } \\
\text { dano }\end{array}$ & $\begin{array}{l}\text { Uma vez a cada } 02 \\
\text { anos }\end{array}$ \\
\hline 02 & Possivel & Baixa probabilidade de ocorrer o dano & $\begin{array}{c}\text { Uma vez a cada } 01 \\
\text { ano }\end{array}$ \\
\hline 03 & Ocasional & $\begin{array}{c}\text { Moderada probabilidade de ocorrer o } \\
\text { dano }\end{array}$ & $\begin{array}{l}\text { Uma vez a cada } \\
\text { semestre }\end{array}$ \\
\hline 04 & Regular & Elevada probabilidade de ocorrer o dane & $\begin{array}{c}\text { Uma vez a cada } 03 \\
\text { meses }\end{array}$ \\
\hline 05 & Certa & $\begin{array}{c}\text { Elevadíssima probabilidade de ocorrer o } \\
\text { dano }\end{array}$ & Uma vez por mês \\
\hline
\end{tabular}

Figura 2: Frequência ou probabilidade de ocorrência de acidentes ou danos. Fonte: Catai (2012). 
Ao se realizar as categorizações com a Tabela 1 (Severidade) e a Tabela 2 (Frequência) estabelecidos, pode-se apresentar a matriz para avaliação qualitativa de risco dos perigos identificados, conforme a Figura 3 apresentada por Catai (2012). Os índices de riscos são calculados realizando o produto da frequência pela severidade.

\begin{tabular}{|c|c|c|}
\hline INDICE DE RISCO & Tipo de risco & NIVEL DE AÇŌES \\
\hline até 03 (severidade < 03 ) & Riscos Triviais & $\begin{array}{l}\text { Não necessitam açōes especiais, nem preventivas, } \\
\text { nem de deteç̧ão. }\end{array}$ \\
\hline $\begin{array}{c}\text { de } 04 \text { a } 06 \text { (severidade }< \\
\text { 04) }\end{array}$ & $\begin{array}{c}\text { Riscos } \\
\text { Toleráveis }\end{array}$ & $\begin{array}{l}\text { Não requerem ações imediatas. Poderão ser } \\
\text { implementadas em ocasião oportuna, em função } \\
\text { das disponibilidades de mão de obra e recursos } \\
\text { financeiros. }\end{array}$ \\
\hline $\begin{array}{c}\text { de } 08 \text { a } 10 \text { (severidade }< \\
05 \text { ) } \\
\end{array}$ & $\begin{array}{c}\text { Riscos } \\
\text { Moderados }\end{array}$ & $\begin{array}{l}\text { Requer previsão e definição de prazo (curto prazo) } \\
\text { e responsabilidade para a implementação das } \\
\text { ações. }\end{array}$ \\
\hline de 12 a 20 & $\begin{array}{c}\text { Riscos } \\
\text { Relevantes }\end{array}$ & $\begin{array}{l}\text { Exige a implementação imediata das açōes } \\
\text { (preventivas e de deteç̧ão) e definição de } \\
\text { responsabilidades. O trabalho pode ser liberado p/ } \\
\text { execução somente c/ acompanhamento } \\
\text { monitoramento contínuo. A interrupção do } \\
\text { trabalho pode acontecer quando as condiçôes } \\
\text { apresentarem algum descontrole. }\end{array}$ \\
\hline$>20$ & $\begin{array}{l}\text { Riscos } \\
\text { Intoleráveis }\end{array}$ & $\begin{array}{l}\text { Os trabalhos não poderăo ser iniciados e se estiver } \\
\text { em curso, deverấo ser interrompidos de imediato } \\
\text { somente poderão ser reiniciados após } \\
\text { implementação de ações de contençâo. }\end{array}$ \\
\hline
\end{tabular}

Figura 3: Índice de risco e gerenciamento das ações a serem tomadas. Fonte: Catai (2012).

\section{RESULTADOS E DISCUSSÃO}

\section{Identificação e avaliação de riscos}

Existem diversas ferramentas de análise de risco sendo utilizadas no universo corporativo. Os métodos utilizados se diferenciam principalmente pelo tipo de empreendimento analisado e pela fase em que a análise do risco será realizada. Durante a aplicação da técnica APR na obra, coordenou-se de uma forma sistemática o grupo de trabalho com os serventes de pedreiro, pedreiro e armador de ferragem, explorando o conhecimento dos mesmos, para adequar o formulário às reais necessidades da obra e da atividade em questão, bem como, a divisão de subsistemas e seu funcionamento e preenchimento do formulário. Foram realizadas anotações e captura de imagens a respeito da possibilidade da ocorrência de acidentes em cada subsistema, suas possíveis causas e efeitos, além de discutir medidas preventivas. Abordaram-se todos os tipos de risco possíveis, tais como: riscos físicos, químicos, biológicos, ergonômicos e acidentes. Na tabela 1 apresenta-se a Análise Preliminar de Risco realizada em campo juntamente com os trabalhadores da obra.

Tabela 1: Análise Preliminar de Risco realizado em campo.

\begin{tabular}{|c|c|c|c|c|c|c|c|}
\hline \multicolumn{8}{|c|}{ ANÁLISE PRELIMINAR DE RISCO (APR) } \\
\hline \multicolumn{8}{|c|}{ Processo: Locação da obra } \\
\hline $\begin{array}{l}\text { Etapa do } \\
\text { processo }\end{array}$ & Risco & Causa & Consequências & Freq. & Sev. & Ris. & $\begin{array}{l}\text { Procedimentos de } \\
\text { segurança recomendados } \\
\text { / medidas preventivas }\end{array}$ \\
\hline \multirow{3}{*}{$\begin{array}{l}1 . \\
\text { Marcação } \\
\text { topográfica }\end{array}$} & 1. Atropelamento & Uso de veículo & Lesões & 1 & 2 & 2 & $\begin{array}{l}\text { Boa sinalização, } \\
\text { colaborador no local } \\
\text { adequado para execução } \\
\text { do trabalho. }\end{array}$ \\
\hline & $\begin{array}{l}\text { 2. Pancadas nas } \\
\text { mãos (prensagem) }\end{array}$ & Cravar estacas & Lesões e contusão & 4 & 4 & 16 & $\begin{array}{l}\text { Uso de luvas adequadas } \\
\text { para função. }\end{array}$ \\
\hline & 3. Corte e & Manuseio de & Corte & 4 & 2 & 8 & Uso de luvas adequadas \\
\hline
\end{tabular}




\begin{tabular}{|c|c|c|c|c|c|c|c|}
\hline & $\begin{array}{l}\text { perfurações } \\
\text { (farpas) }\end{array}$ & estacas & & & & & $\begin{array}{l}\text { para função, uso de bota } \\
\text { de borracha cano longo. }\end{array}$ \\
\hline & $\begin{array}{l}\text { 4. Radiações não } \\
\text { ionizantes } \\
\text { (radiação solar) }\end{array}$ & $\begin{array}{l}\text { Permanecer na } \\
\text { obra a céu } \\
\text { aberto }\end{array}$ & $\begin{array}{l}\text { Queimaduras e } \\
\text { lesões na pele }\end{array}$ & 3 & 3 & 9 & $\begin{array}{l}\text { Uso de uniforme de } \\
\text { algodão com mangas } \\
\text { compridas e protetor } \\
\text { solar. }\end{array}$ \\
\hline & $\begin{array}{l}\text { 5. Uso de } \\
\text { ferramenta } \\
\text { inadequada } \\
\end{array}$ & $\begin{array}{l}\text { Ferramentas de } \\
\text { trabalho }\end{array}$ & $\begin{array}{l}\text { Fratura, luxações e } \\
\text { lesão }\end{array}$ & 3 & 2 & 6 & $\begin{array}{l}\text { Ferramentas sempre em } \\
\text { bom estado. }\end{array}$ \\
\hline $\begin{array}{l}\text { Etapa do } \\
\text { processo }\end{array}$ & Risco & Causa & Consequências & Freq. & Sev. & Ris. & $\begin{array}{l}\text { Procedimentos de } \\
\text { segurança recomendados } \\
\text { / medidas preventivas }\end{array}$ \\
\hline \multirow{7}{*}{$\begin{array}{l}2 . \\
\text { Escavação }\end{array}$} & $\begin{array}{l}\text { 6. Ruído contínuo } \\
\text { ou intermitente }\end{array}$ & $\begin{array}{l}\text { Ambiente da } \\
\text { obra e operar } \\
\text { máquinas e } \\
\text { equipamentos } \\
\text { necessários } \\
\end{array}$ & $\begin{array}{l}\text { Dor de cabeça, } \\
\text { surdez temporária, } \\
\text { perda auditiva } \\
\text { permanente }\end{array}$ & 2 & 3 & 6 & Uso de protetor auricular. \\
\hline & $\begin{array}{l}\text { 7. Pancadas } \\
\text { generalizadas }\end{array}$ & $\begin{array}{l}\text { Movimentação } \\
\text { de equipamento } \\
\text { e ferramentas }\end{array}$ & $\begin{array}{l}\text { Contusão, lesão } \\
\text { grave }\end{array}$ & 4 & 3 & 12 & $\begin{array}{l}\text { Permanecer distante do } \\
\text { giro da escavadeira. }\end{array}$ \\
\hline & $\begin{array}{l}\text { 8. Queda de } \\
\text { funcionário }\end{array}$ & $\begin{array}{l}\text { Mudança de } \\
\text { nível }\end{array}$ & Lesão & 4 & 3 & 12 & $\begin{array}{l}\text { Delimitar com cones e fita } \\
\text { zebrada limite de risco. }\end{array}$ \\
\hline & $\begin{array}{l}\text { 9. Radiações não } \\
\text { ionizantes } \\
\text { (radiação solar) }\end{array}$ & $\begin{array}{l}\text { Permanecer na } \\
\text { obra a céu } \\
\text { aberto }\end{array}$ & $\begin{array}{l}\text { Queimaduras e } \\
\text { lesões na pele }\end{array}$ & 3 & 3 & 9 & $\begin{array}{l}\text { Uso de uniforme de } \\
\text { algodão com mangas } \\
\text { compridas e protetor solar }\end{array}$ \\
\hline & 10. Vibrações & $\begin{array}{l}\text { Máquinas e } \\
\text { equipamentos } \\
\text { utilizados na } \\
\text { obra }\end{array}$ & $\begin{array}{l}\text { Cansaço, irritação, } \\
\text { dores nos } \\
\text { membros, dores } \\
\text { na coluna }\end{array}$ & 2 & 2 & 4 & $\begin{array}{l}\text { Revezamento de } \\
\text { funcionários, } \\
\text { amortecedores nos } \\
\text { bancos e luvas anti- } \\
\text { vibração }\end{array}$ \\
\hline & 11. Poeiras & $\begin{array}{l}\text { Serviços de } \\
\text { escavação }\end{array}$ & Pneumoconioses & 3 & 3 & 9 & $\begin{array}{l}\text { Solicitada atenção dos } \\
\text { funcionários envolvidos na } \\
\text { frente de serviço, e } \\
\text { utilização de EPIs } \\
\text { (máscaras adequadas ao } \\
\text { agente químico) }\end{array}$ \\
\hline & $\begin{array}{l}12 . \\
\text { Desmoronamento } \\
\text { e soterramento }\end{array}$ & $\begin{array}{l}\text { Durante a } \\
\text { escavação do } \\
\text { solo (talude) }\end{array}$ & $\begin{array}{l}\text { Tombamento do } \\
\text { equipamento, } \\
\text { soterramento e } \\
\text { asfixia }\end{array}$ & 4 & 4 & 16 & $\begin{array}{l}\text { Estudar em todo } \\
\text { deslocamento da máquina } \\
\text { a resistência do terreno, } \\
\text { observar existências de } \\
\text { redes subterrâneas, } \\
\text { cuidado com } \\
\text { comprometimento da } \\
\text { estabilidade sob a } \\
\text { máquina. Isolamento da } \\
\text { área }\end{array}$ \\
\hline
\end{tabular}

\begin{tabular}{|l|l|l|l|l|l|l|l|}
\hline \multicolumn{1}{|c|}{$\begin{array}{l}\text { Etapa do } \\
\text { processo }\end{array}$} & \multicolumn{1}{|c|}{ Risco } & \multicolumn{1}{|c|}{ Causa } & Consequências & Freq. & Sev. & $\begin{array}{l}\text { Procedimentos de } \\
\text { segurança } \\
\text { Recomendados / } \\
\text { medidas } \\
\text { preventivas }\end{array}$ \\
\hline \multirow{2}{*}{$\begin{array}{l}\text { 3. Regularização } \\
\text { com } \\
\text { retroescavadeira }\end{array}$} & $\begin{array}{l}\text { 13. } \\
\text { Desmoronamento } \\
\text { e soterramento }\end{array}$ & $\begin{array}{l}\text { Do solo } \\
\text { escavado/talude }\end{array}$ & $\begin{array}{l}\text { Tombamento do } \\
\text { equipamento, } \\
\text { soterramento, } \\
\text { lesões }\end{array}$ & 4 & 4 & 16 & $\begin{array}{l}\text { Nunca escavar em } \\
\text { caixote, proibir } \\
\text { aproximação de } \\
\text { equipamentos } \\
\text { pesados na borda } \\
\text { da vala }\end{array}$ \\
\cline { 2 - 7 } & $\begin{array}{l}\text { 14. Ruído contínuo } \\
\text { ou intermitente }\end{array}$ & $\begin{array}{l}\text { Ambiente da obra } \\
\text { e operar máquinas } \\
\text { e equipamentos } \\
\text { necessários }\end{array}$ & $\begin{array}{l}\text { Dor de cabeça, } \\
\text { surdez } \\
\text { temporária, } \\
\text { perda auditiva } \\
\text { permanente }\end{array}$ & 2 & 3 & 6 & $\begin{array}{l}\text { Uso de protetor } \\
\text { auricular }\end{array}$ \\
\cline { 2 - 7 } & 15. Pancadas & $\begin{array}{l}\text { Movimentação de } \\
\text { equipamento e } \\
\text { ferramentas }\end{array}$ & $\begin{array}{l}\text { Contusão, lesão } \\
\text { grave }\end{array}$ & 4 & 3 & 12 \\
\hline
\end{tabular}




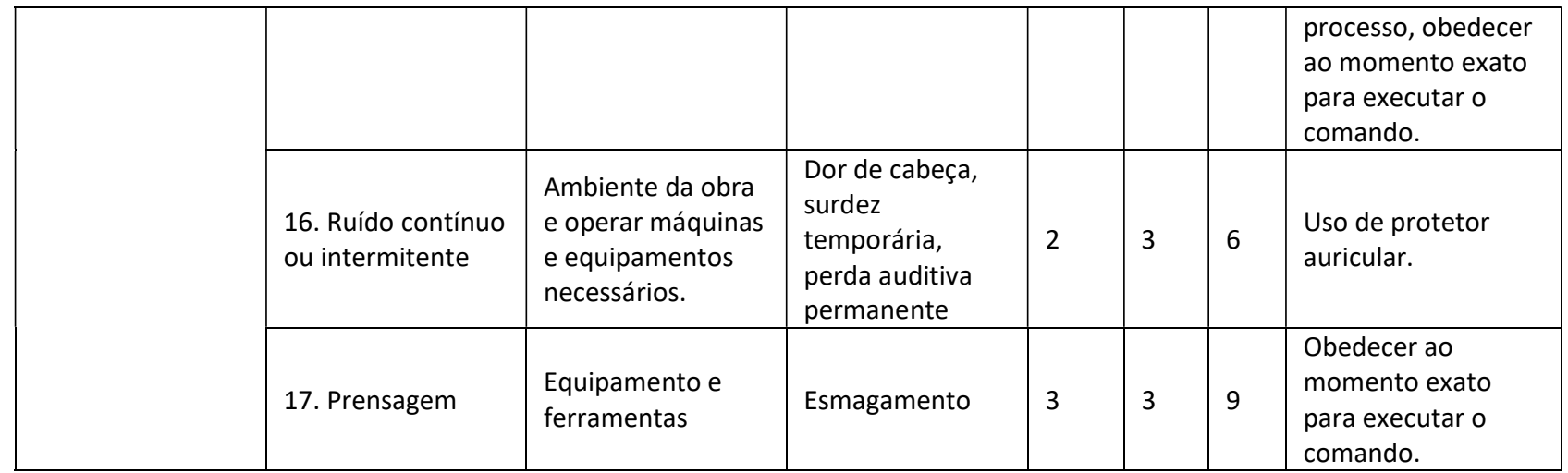

\begin{tabular}{|c|c|c|c|c|c|c|c|}
\hline \multicolumn{8}{|c|}{ Processo: Execução de Elementos Estruturais de Concreto Armado } \\
\hline $\begin{array}{l}\text { Etapa do } \\
\text { processo }\end{array}$ & Risco & Causa & Consequências & Freq. & Sev. & Ris. & $\begin{array}{c}\text { Procedimentos de } \\
\text { segurança recomendados / } \\
\text { medidas preventivas }\end{array}$ \\
\hline \multirow{4}{*}{$\begin{array}{l}4 . \\
\text { Montagem } \\
\text { de } \\
\text { Armaduras } \\
\text { de Aço }\end{array}$} & $\begin{array}{l}\text { Corte/ } \\
\text { Perfuração }\end{array}$ & $\begin{array}{l}\text { Manuseio } \\
\text { incorreto de } \\
\text { ferramentas, não } \\
\text { utilização de EPI } \\
\text { adequado }\end{array}$ & $\begin{array}{l}\text { Lesões físicas, } \\
\text { diminuição da } \\
\text { produtividade }\end{array}$ & 5 & 2 & 10 & $\begin{array}{l}\text { Utilização de EPI adequado } \\
\text { e realização de } \\
\text { treinamentos. }\end{array}$ \\
\hline & $\begin{array}{l}\text { Queda em } \\
\text { altura }\end{array}$ & $\begin{array}{l}\text { Não utilização do } \\
\text { cinto de } \\
\text { segurança, falta } \\
\text { de manutenção do } \\
\text { EPI, Falta de } \\
\text { treinamento }\end{array}$ & $\begin{array}{l}\text { Fraturas, } \\
\text { Escoriações, Óbito }\end{array}$ & 4 & 3 & 12 & $\begin{array}{l}\text { Utilização de EPI adequado, } \\
\text { realização de treinamentos } \\
\text { para trabalho em altura e } \\
\text { adoção de medidas } \\
\text { recomendadas para } \\
\text { trabalhos em altura. }\end{array}$ \\
\hline & $\begin{array}{l}\text { Dores nas } \\
\text { costas e } \\
\text { membros }\end{array}$ & $\begin{array}{l}\text { Adoção de } \\
\text { posturas } \\
\text { inadequadas, } \\
\text { movimentos } \\
\text { repetitivos, } \\
\text { Ausência de } \\
\text { intervalos para } \\
\text { descanso }\end{array}$ & $\begin{array}{l}\text { Lesões por esforço } \\
\text { repetitivo (LER), } \\
\text { Lesões musculares, } \\
\text { fadiga, diminuição } \\
\text { da produtividade. }\end{array}$ & 4 & 2 & 8 & $\begin{array}{l}\text { Realização de ginástica } \\
\text { laboral com os } \\
\text { trabalhadores, adoção de } \\
\text { intervalos de descanso } \\
\text { compatíveis com as tarefas } \\
\text { realizadas durante a } \\
\text { jornada de trabalho e } \\
\text { realização de treinamentos. }\end{array}$ \\
\hline & $\begin{array}{l}\text { Quedas de } \\
\text { objetos de } \\
\text { pavimentos } \\
\text { superiores }\end{array}$ & $\begin{array}{l}\text { Falta de atenção, } \\
\text { manuseio } \\
\text { incorreto de } \\
\text { ferramentas, falta } \\
\text { de treinamentos }\end{array}$ & Lesões físicas, Óbito. & 5 & 2 & 10 & $\begin{array}{l}\text { Realização de } \\
\text { treinamentos, uso de telas } \\
\text { nas fachadas e uso de } \\
\text { bandejas de proteção. }\end{array}$ \\
\hline
\end{tabular}

\begin{tabular}{|c|c|c|c|c|c|c|c|}
\hline \multicolumn{8}{|c|}{ Processo: Execução de Elementos Estruturais de Concreto Armado } \\
\hline $\begin{array}{l}\text { Etapa do } \\
\text { processo }\end{array}$ & Risco & Causa & Consequências & Freq. & Sev. & Ris. & $\begin{array}{c}\text { Procedimentos } \\
\text { de segurança } \\
\text { recomendados } \\
\text { / medidas } \\
\text { preventivas }\end{array}$ \\
\hline \multirow{2}{*}{$\begin{array}{l}5 . \\
\text { Montagem } \\
\text { de Fôrmas }\end{array}$} & $\begin{array}{l}\text { Corte/ Perfuração/ Esmagamento de } \\
\text { Dedos }\end{array}$ & $\begin{array}{l}\text { Manuseio } \\
\text { incorreto de } \\
\text { ferramentas, } \\
\text { não utilização } \\
\text { de EPI } \\
\text { adequado }\end{array}$ & $\begin{array}{l}\text { Lesões físicas, } \\
\text { diminuição da } \\
\text { produtividade }\end{array}$ & 5 & 2 & 10 & $\begin{array}{l}\text { Utilização de } \\
\text { EPI adequado e } \\
\text { realização de } \\
\text { treinamentos. }\end{array}$ \\
\hline & Queda em altura & $\begin{array}{l}\text { Não utilização } \\
\text { do cinto de } \\
\text { segurança, } \\
\text { falta de }\end{array}$ & $\begin{array}{l}\text { Fraturas, } \\
\text { Escoriações, } \\
\text { Óbito }\end{array}$ & 4 & 3 & 12 & $\begin{array}{l}\text { Utilização de } \\
\text { EPI adequado, } \\
\text { realização de } \\
\text { treinamentos }\end{array}$ \\
\hline
\end{tabular}




\begin{tabular}{|c|c|c|c|c|c|c|}
\hline & $\begin{array}{l}\text { manutenção } \\
\text { do EPI, Falta } \\
\text { de } \\
\text { treinamento }\end{array}$ & & & & & $\begin{array}{l}\text { para trabalho } \\
\text { em altura e } \\
\text { adoção de } \\
\text { medidas } \\
\text { recomendadas } \\
\text { para trabalhos } \\
\text { em altura. }\end{array}$ \\
\hline Dores nas costas e membros & $\begin{array}{l}\text { Adoção de } \\
\text { posturas } \\
\text { inadequadas, } \\
\text { movimentos } \\
\text { repetitivos, } \\
\text { Ausência de } \\
\text { intervalos } \\
\text { para descanso }\end{array}$ & $\begin{array}{l}\text { Lesões por } \\
\text { esforço } \\
\text { repetitivo } \\
\text { (LER), Lesões } \\
\text { musculares, } \\
\text { Fadiga, } \\
\text { Diminuição da } \\
\text { produtividade }\end{array}$ & 4 & 2 & 8 & $\begin{array}{l}\text { Realização de } \\
\text { ginástica } \\
\text { laboral com os } \\
\text { trabalhadores, } \\
\text { adoção de } \\
\text { intervalos de } \\
\text { descanso } \\
\text { compatíveis } \\
\text { com as tarefas } \\
\text { realizadas } \\
\text { durante a } \\
\text { jornada de } \\
\text { trabalho e } \\
\text { realização de } \\
\text { treinamentos. }\end{array}$ \\
\hline $\begin{array}{l}\text { Queimaduras/Intoxicações/Irritações } \\
\text { na pele }\end{array}$ & $\begin{array}{l}\text { Manuseio } \\
\text { incorreto de } \\
\text { produtos } \\
\text { químicos } \\
\text { desmoldantes } \\
\text { para auxiliar } \\
\text { na retirada } \\
\text { das formas }\end{array}$ & $\begin{array}{l}\text { Lesões na pele, } \\
\text { Queimaduras, } \\
\text { Intoxicação, } \\
\text { Irritações na } \\
\text { pele }\end{array}$ & 3 & 2 & 6 & $\begin{array}{l}\text { Utilização de } \\
\text { EPI adequado, } \\
\text { realização de } \\
\text { treinamentos }\end{array}$ \\
\hline $\begin{array}{l}\text { Quedas de objetos de pavimentos } \\
\text { superiores }\end{array}$ & $\begin{array}{l}\text { Falta de } \\
\text { atenção, } \\
\text { manuseio } \\
\text { incorreto de } \\
\text { ferramentas, } \\
\text { falta de } \\
\text { treinamento }\end{array}$ & $\begin{array}{l}\text { Lesões físicas, } \\
\text { Óbito }\end{array}$ & 5 & 2 & 10 & $\begin{array}{l}\text { Realização de } \\
\text { treinamentos, } \\
\text { uso de telas nas } \\
\text { fachadas e uso } \\
\text { de bandejas de } \\
\text { proteção. }\end{array}$ \\
\hline
\end{tabular}

\begin{tabular}{|c|c|c|c|c|c|c|c|}
\hline \multicolumn{8}{|c|}{ Processo: Execução de Elementos Estruturais de Concreto Armado } \\
\hline $\begin{array}{l}\text { Etapa do } \\
\text { processo }\end{array}$ & Risco & Causa & Consequências & Freq. & Sev. & Ris. & $\begin{array}{l}\text { Procedimentos de } \\
\text { segurança recomendados } \\
\text { / medidas preventivas }\end{array}$ \\
\hline \multirow{4}{*}{$\begin{array}{l}6 . \\
\text { Concretagem } \\
\text { da Peça } \\
\text { Estrutural }\end{array}$} & $\begin{array}{l}\text { Vibrações } \\
\text { Excessivas }\end{array}$ & $\begin{array}{l}\text { Manuseio do } \\
\text { vibrador para } \\
\text { adensamento do } \\
\text { concreto por } \\
\text { tempo prolongado } \\
\text { ou de forma } \\
\text { incorreta }\end{array}$ & $\begin{array}{l}\text { Lesões musculares, } \\
\text { Fadiga, Diminuição } \\
\text { da produtividade }\end{array}$ & 3 & 2 & 6 & $\begin{array}{l}\text { Adoção de intervalos de } \\
\text { descanso, revezamento } \\
\text { de trabalhadores na } \\
\text { função, utilização de EPI } \\
\text { adequado, realização de } \\
\text { treinamentos }\end{array}$ \\
\hline & $\begin{array}{l}\text { Queda em } \\
\text { altura }\end{array}$ & $\begin{array}{l}\text { Não utilização do } \\
\text { cinto de } \\
\text { segurança, falta de } \\
\text { manutenção do } \\
\text { EPI, Falta de } \\
\text { treinamento }\end{array}$ & $\begin{array}{l}\text { Fraturas, } \\
\text { Escoriações, Óbito }\end{array}$ & 4 & 3 & 12 & $\begin{array}{l}\text { Utilização de EPI } \\
\text { adequado, realização de } \\
\text { treinamentos para } \\
\text { trabalho em altura e } \\
\text { adoção de medidas } \\
\text { recomendadas para } \\
\text { trabalhos em altura. }\end{array}$ \\
\hline & $\begin{array}{l}\text { Dores nas } \\
\text { costas e } \\
\text { membros }\end{array}$ & $\begin{array}{l}\text { Adoção de } \\
\text { posturas } \\
\text { inadequadas, } \\
\text { movimentos } \\
\text { repetitivos, } \\
\text { Ausência de } \\
\text { intervalos para } \\
\text { descanso }\end{array}$ & $\begin{array}{l}\text { Lesões por esforço } \\
\text { repetitivo (LER), } \\
\text { Lesões musculares, } \\
\text { Fadiga, Diminuição } \\
\text { da produtividade }\end{array}$ & 4 & 2 & 8 & $\begin{array}{l}\text { Realização de ginástica } \\
\text { laboral com os } \\
\text { trabalhadores, adoção de } \\
\text { intervalos de descanso } \\
\text { compatíveis com as } \\
\text { tarefas realizadas durante } \\
\text { a jornada de trabalho e } \\
\text { realização de } \\
\text { treinamentos. }\end{array}$ \\
\hline & Quedas de & Falta de atenção, & Lesões físicas, Óbito & 5 & 2 & 10 & Realização de \\
\hline
\end{tabular}




\begin{tabular}{|l|l|l|l|l|l|l|l|}
\hline & $\begin{array}{l}\text { objetos de } \\
\text { pavimentos } \\
\text { superiores }\end{array}$ & $\begin{array}{l}\text { manuseio } \\
\text { incorreto de } \\
\text { ferramentas, falta } \\
\text { de treinamento }\end{array}$ & & & & $\begin{array}{l}\text { treinamentos, uso de } \\
\text { telas nas fachadas e uso } \\
\text { de bandejas de proteção. }\end{array}$ \\
\hline
\end{tabular}

\section{CONCLUSÕES}

O ramo da construção civil apesar de ser muito importante para a economia brasileira, também é um dos setores com maior número de acidentes de trabalho. Portanto, a utilização de técnicas que visem à implantação de medidas de segurança no trabalho é muito importante. No processo de locação da obra e no processo de execução de elementos estruturais de concreto armado podem ser identificados diversos cenários que podem colocar em risco a integridade física dos trabalhadores.

A utilização da Análise Preliminar de Riscos em processos da construção civil pode contribuir de maneira bastante satisfatória para a mudança do quadro de elevados números de acidentes e doenças ocupacionais que atingem o setor. Portanto, a utilização da APR na construção civil é eficiente, pois nos permite ter uma visão geral dos perigos envolvidos em determinado processo e também identificar aqueles de maior impacto para a saúde e segurança dos trabalhadores.

\section{REFERÊNCIAS}

CATAI, R. E.. Ferramentas de Gerência de Riscos. Apostila elaborada para o curso de engenharia de segurança do trabalho. Curitiba: UTFPR, 2012.

FARIA, M. T.. Gerência de riscos: apostila do curso de especialização em engenharia de segurança do trabalho. Curitiba: UTFPR, 2011.

FRANÇA, S. L. B.; TOZE, M. A.; QUELHAS, O. L. G.. A gestão de pessoas como contribuição à implantação da gestão de riscos. O caso da indústria da construção civil. Revista Produção Online, v.8, n.4, 2008.

IBGE. Instituto Brasileiro de Geografia e Estatística. Contas Nacionais Trimestrais: Indicadores de Volume e Valores Correntes. Rio de Janeiro: IBGE, 2018.

MARTINELLI FILHO, W.; PONTES, J. C. A.. O Panorama Atual dos Acidentes de Trabalho na Construção: Uma Análise a Partir do Anuário Estatístico da Previdência Social: Triênio 2013 a 2015. Revista Científica Multidisciplinar Núcleo do Conhecimento, v.4, n.2, p.19-29, 2018.
OIT. Organização Internacional do Trabalho. Acidentalidade no mundo. Anuário Brasileiro de Proteção 2017. Genebra: OIT, 2017.

SHERIQUE, J.. Aprenda como fazer. 7 ed. São Paulo: LTr, 2011.

SILVA, E. F.; APPIO, J.; VIEIRA, V. A.. Um estudo da satisfação dos colaboradores de uma empresa de materiais elétricos a partir da Técnica de Incidente Crítico. Synergismus Scyentifica, v.3, n.1, 2008.

TAVARES, J. C.. Noções de Prevenção e controle de perdas em Segurança do Trabalho. São Paulo: Senac, 2010.

YI, J.; KIMB, Y.; KIMC, K.; KOOD, B.. A suggested color scheme for reducing perception-related accidents on construction work sites. Accident analysis and prevention, v.48, p.185-192, 2012.

A CBPC - Companhia Brasileira de Produção Científica (CNPJ: 11.221.422/0001-03) detém os direitos materiais desta publicação. Os direitos referem-se à publicação do trabalho em qualquer parte do mundo, incluindo os direitos às renovações, expansões e disseminações da contribuição, bem como outros direitos subsidiários. Todos os trabalhos publicados eletronicamente poderão posteriormente ser publicados em coletâneas impressas sob coordenação da Sustenere Publishing, da Companhia Brasileira de Produção Científica e seus parceiros autorizados. Os (as) autores (as) preservam os direitos autorais, mas não têm permissão para a publicação da contribuição em outro meio, impresso ou digital, em português ou em tradução. 